\title{
Hour Squared Times Micromole Per Liter
}

National Cancer Institute

\section{Source}

National Cancer Institute. Hour Squared Times Micromole Per Liter. NCI Thesaurus.

Code C106528.

Hours squared times micromoles per liter. 